\title{
Smart and Hybrid Balancing System: Design, Modeling and Experimental Demonstration
}

\author{
Ricardo de Castro, Senior Member, IEEE, Cláudio Pinto, Jorge Varela Barreras, Member, IEEE, \\ Rui Esteves Araújo, Member, IEEE, and David A. Howey, Senior Member, IEEE
}

\begin{abstract}
Performance of series connected batteries is limited by the 'weakest link' effect, i.e. the cell or group of cells with the poorest performance in terms of temperature, power, or energy characteristics. To mitigate the 'weakest link' effect, this study deals with the design, modeling and experimental demonstration of a smart and hybrid balancing system (SHBS). A cell-to-cell shared energy transfer configuration is proposed, including a supercapacitor bank in the balancing bus, thus enabling hybridization. Energy is transferred from each battery module connected in series to the balancing bus, and vice versa, by means of low-cost bi-directional dc-dc converters. The current setpoints of the converters are obtained by means of a smart balancing control strategy, implemented using convex optimization. The strategy is called 'smart' because it pursues goals beyond conventional state-of-charge equalization, including temperature and power capability equalization, and minimization of energy losses. Simulations show that the proposed SHBS is able to achieve all these goals effectively in an e-mobility application, and are also used to assess the impact of different hybridization ratios and cooling conditions. Finally, an experimental setup is developed to demonstrate the feasibility of the SHBS.
\end{abstract}

Index Terms-battery management system, supercapacitors, convex optimization, hybrid energy storage system, battery balancing

\section{INTRODUCTION}

One of the main issues in the design of battery-based electric vehicles (EVs) is the non-uniformity in the capacity, inner resistance and thermal characteristics of the battery cells, which may result in performance degradation, limited by the cell with the poorer performance, i.e. the 'weakest-cell

Copyright (c) 2015 IEEE. Personal use of this material is permitted. However, permission to use this material for any other purposes must be obtained from the IEEE by sending a request to pubs-permissions@ieee.org.

Ricardo de Castro is with Institute of System Dynamics and Control, German Aerospace Center (DLR), Wessling, D-82234, Germany (e-mail: Ricardo.DeCastro@dlr.de). His work was funded by the project Next Generation Car, Antriebsstrang und Energiemanagement.

Cláudio Pinto and Rui Esteves Araújo are with INESC TEC and Faculty of Engineering, University of Porto, Porto, 4200-465, Portugal (e-mail: dee12015@fe.up.pt, raraujo@fe.up.pt). Their work was funded by FCT-Fundação para a Ciência e a Tecnologia, within the project SAICTPAC/0004/2015-POCI-01-0145-FEDER-016434 and scholarship SFRH/BD/90490/2012.

Jorge Varela Barreras is with the Department of Mechanical Engineering, Imperial College London, London, UK (email: jvarelab@ic.ac.uk), and The Faraday Institution, Quad One, Harwell Science and Innovation Campus, Didcot, UK. He was with the Department of Engineering Science, University of Oxford, UK, until the end of 2018. His work was sponsored by Faraday Institution (faraday.ac.uk; EP/S003053/1), grant number FIRG003

David A. Howey is with Department of Engineering Science, University of Oxford, Oxford, OX1 3PJ, UK (e-mail: david.howey@eng.ox.ac.uk). He acknowledges funding from the STFC Batteries Network (ST/N002385/1) and the Energy Storage for Low Carbon Grids Project (EPSRC reference $\mathrm{EP} / \mathrm{K} 002252 / 1)$ problem' [1]. To minimize operational unbalances resulting from these mismatches, active and passive balancing systems can be implemented. In the passive case, energy from the cells with the highest voltages is dissipated as heat, e.g. through shunt resistors (see Fig. 1a). Despite being simple, this approach is affected by high thermal losses [2].

Active balancing uses power converters to re-distribute energy through the battery pack. It offers higher energy efficiency, potential for state-of-charge (SoC) [3] and thermal equalization [4], [5], but suffers from higher costs and complexity [2]. In the literature, several types of active balancing topologies have been proposed, including, for example, cell-topack, pack-to-cell and cell-to-cell configurations (see Fig. 1a). In cell-to-pack configurations [6], [7] the excess energy of the cells is transferred to the battery pack, while pack-tocell [2] performs the inverse operation, i.e. weaker cells receive energy from the pack. Cell-to-cell topologies allow the transfer between individual cells; they can be divided into distributed variants [8] (transfer of energy is only allowed between neighbor cells) and shared [9], [10] (energy is first transferred to an energy accumulator and then moved to another cell). In our previous research [11], a benchmarking of several balancing configurations was performed. It was concluded that the cell-to-cell shared (CCS) is one of most promising battery balancing configurations, offering superior energy efficiency and thermal performance. Building on these previous findings, the main aim of this work is to enhance CCS configurations with an additional feature: hybridization of batteries with supercapacitors (SCs).

The battery-SC hybridization is driven by the idea of combining energy storage units with complementary characteristics, such that the resulting hybrid energy storage system (HESS) provides better overall performance [12], [13]. Given their high power density, high number of charge-discharge cycles and efficiency, SCs are well suited to support the operation of batteries. In particular, batteries with higher energy density usually provide the average power of the vehicle, while SCs with higher power density, but lower energy density, handle power transients. Numerous studies have demonstrated that battery-SC hybridization is able to reduce peak currents and degradation of the battery pack [14]-[18], increasing the lifetime [19], [20] and potential value of batteries for secondlife applications, such as grid support [21]. However, SCs also increase costs, weight and volume, which introduce trade-offs in the design and sizing of the battery-SC HESS [19], [22].

The hybridization of battery and SCs can be classified in terms of degrees of freedom available to control: $i$ ) the 


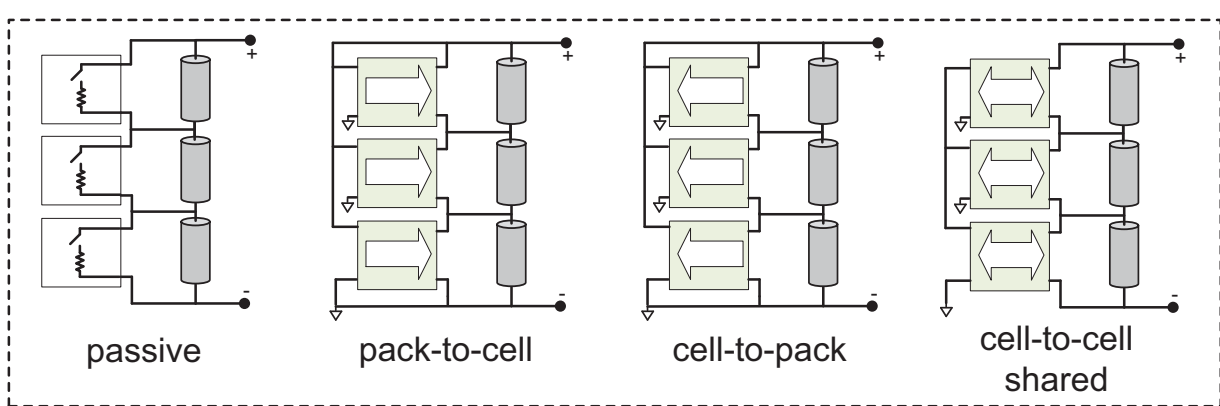

(a) balancing systems

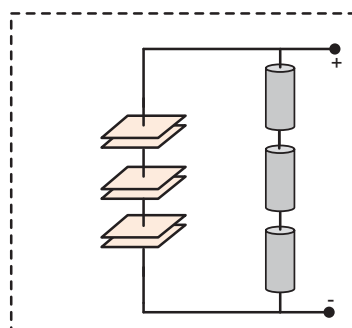

OD hybridization

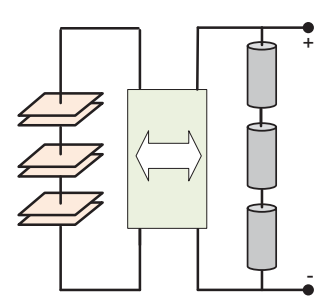

1D hybridization

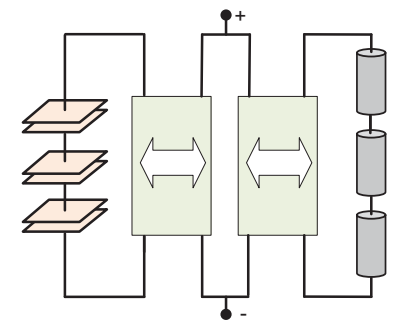

2D hybridization

(b) battery-SC hybridization

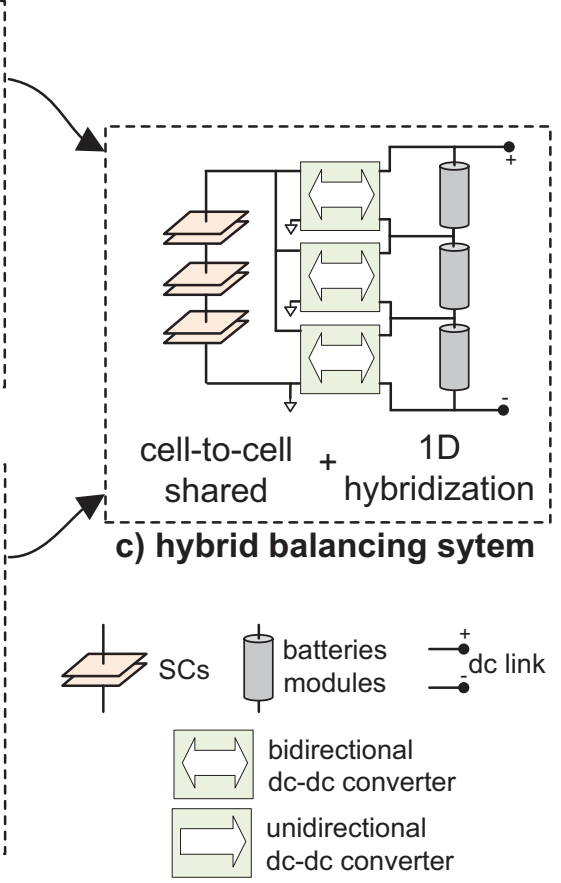

Fig. 1. Representation of some state-of-art balancing topologies (a), battery-supercapacitors hybridization configurations (b) and the proposed hybrid balancing concept (c). Note: to simplify the presentation only 3 battery modules are shown.

power provided by the energy storage units, and $i i$ ) the dclink voltage, which connects the energy storage unit with the vehicle's driveline (see Fig. 1b). In configurations with zero degrees $(O D)$ of freedom, also known as passive hybridization, the SCs are directly connected to the batteries [23], [24]. Due to the absence of power electronics, this solution is the most affordable. However, the power split is dictated by the inner impedance of the storage units and the dc-link voltage is fixed by the battery terminals, which limits the benefits of this configuration [25]. Hybridization with two degrees (2D) of freedom has dedicated dc-dc power converters for each storage unit, enabling the simultaneous control of the dc-link voltage and power provided by batteries and SCs [15], [16], [18], [26]. Because of the variable dc-link voltage, higher voltages to the vehicle's driveline can be applied, which allows the extension of the maximum speed of the traction motor and reduction of copper losses [27]. The drawback of this approach lies in the increased costs, weight and complexity due to the presence of two power converters. Hybridization with one degree (ID) of freedom provides a good trade-off between costs and performance, since only one power converter is employed. Given the wide operating range of the SCs voltage, the power converter is often connected with this energy unit [14], [19], but no variable dc-link voltage is offered.

The majority of previous research treated the battery balancing and battery-SC hybridization as two separate functions. In contrast, we investigate here the possibility of integrating these two functions into the same system. We exploit the power electronics embedded in the balancing system to simultaneously enable battery balancing and battery-SC hybridization with one degree of freedom (see Fig. 1c). The main advantage of this approach, called smart and hybrid balancing system (SHBS), is the low cost of hybridization, since we avoid the incorporation of additional power converters to actively distribute the power flow in the HESS. It is important to note that previous research, such as [28], [29], also considered the inclusion of SCs in the balancing system. However, these SCs are mainly used as a small energy buffer for balancing purposes; they do not take advantage of the SCs to minimize energy losses or the stress in the battery cells, which is the focus of battery-SC hybridization. Reference [9] uses the balancing circuit to simultaneously achieve battery SoC equalization and charge a low-voltage battery (which supplies power to the auxiliary systems of the vehicle), but no hybridization is pursued.

In summary, our work provides three main contributions. First, we present a feasibility study on the use of a CCS topology to simultaneously perform battery balancing (i.e. SoC and temperature equalization) as well as hybridization with SCs. Second, a convex optimization framework for controlling the hybrid balancing setup is developed. In comparison with other optimization frameworks - such as dynamic programming [20], [30], non-linear optimization [15] or gradientfree algorithms [31] - convex methods offer computationally efficient solutions and attractive theoretical properties (e.g., guarantee of an unique optimum [32]). These advantages have encouraged the application of convex optimization in several automotive applications, including powertrain sizing [33], energy management [34] and battery balancing circuits [11]. To the best of the authors' knowledge, it is the first time that convex methods have been applied to the control of hybrid balancing systems. The third contribution deals with 
the investigation, through numerical simulations, of different balancing configurations, which enables us to quantify benefits of hybrid $v s$ non-hybrid balancing solutions. A preliminary version of this work was published at [35]; it is extended here by expanding the analysis of the SHBS properties and providing experimental validation in a small scale prototype.

The remainder of this paper is organized as follows: Section II discusses the control architecture for the SHBS as well as the energy management and battery balancing problems. These problems are then solved using convex optimization methods in Section III and validated through numerical simulations in Sections IV and V. Experimental validation of the SHBS in a small scale prototype is presented in Section VI, while Section VII provides concluding remarks and outlook for future work.

\section{Hybrid BALANCING System: OVERVIEW}

\section{A. Control Architecture}

As depicted in Fig. 2, the hybrid balancing circuit is composed of $n$ dc-dc converters. The primary side of each dc-dc converter is connected to the terminals of the battery modules ${ }^{1}$, while the secondary side is coupled with an auxiliary energy buffer. In this CCS balancing configuration, the energy of the battery modules is first transferred to the energy buffer and then re-distributed to other modules. Previous applications of this balancing circuit implemented the auxiliary energy buffer though small capacitors, operating as a filter for the output of the dc-dc converter (e.g. flyback-based converters [9], [36]). This work pursues a different route. Our first goal is to increase the size of the secondary energy buffer, through the use of SCs, such that a HESS (batteries + SCs) can be formed. The second goal deals with the control of the dc-dc power converters to simultaneously perform battery balancing and energy management of the HESS.

To achieve these goals a two-layer control structure is adopted (see Fig. 2). The lower layer controls the balancing currents $\left(i_{B, j}, j \in \mathcal{J}=\{1, \ldots, n\}\right)$, via manipulation of the modulation signals of the power converters, and estimates the SoC of the battery modules [37]. The higher layer performs the energy management and battery balancing functions using currents $i_{B, j}$ as control variables. The battery balancing function focuses on $\mathrm{SoC}$ and temperature equalization of the battery modules, while the energy management prioritizes power division between batteries and SCs that minimizes energy losses. In what follows, we will concentrate on the design and evaluation of the higher layer algorithm. Details on the lower layer can be found in [38].

\section{B. Problem Formulation}

The energy management and battery balancing algorithms must cope with three sets of constraints. The first set is related to physical operation limits of the dc-dc converters, which introduce constraints in the allowed range of balancing currents:

$$
\underline{i}_{B} \leq i_{B, j}(t) \leq \bar{i}_{B},
$$

\footnotetext{
${ }^{1}$ in this work, a battery module is comprised of one or more battery cells connected in parallel
}

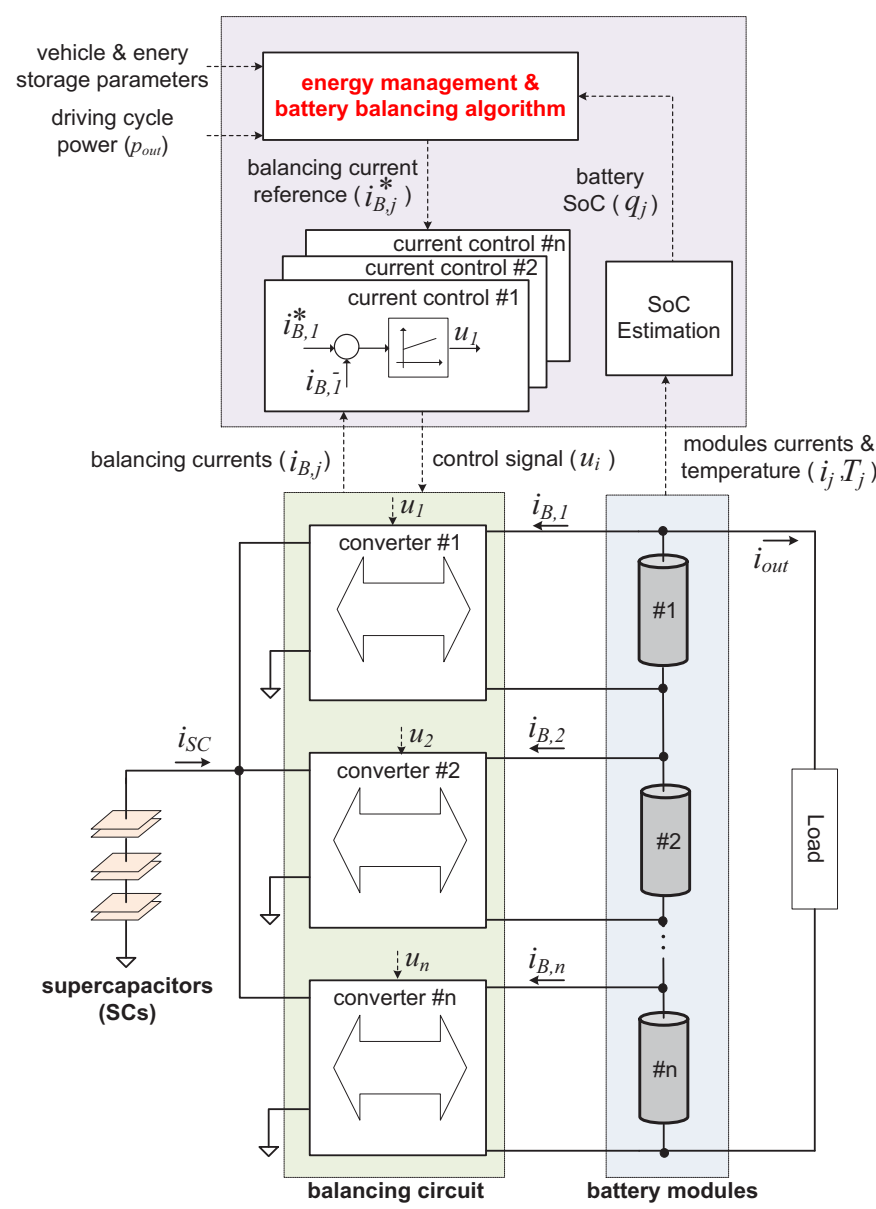

Fig. 2. Overview of the two-layer control structure for the hybrid balancing system. The higher layer provides energy management and battery balancing functions, while the lower layer handles the current control of the power converters.

where $j \in \mathcal{J}, \underline{i}_{B}$ represents the lower bound and $\bar{i}_{B}$ the upper bound of the balancing currents.

The second set of constraints deals with safety limits in the currents $\left(i_{j}, i_{S C}\right)$ and $\operatorname{SoC}\left(q_{j}, q_{S C}\right)$ of both batteries and SCs. This means:

$$
\begin{gathered}
\underline{i}_{j} \leq i_{j}(t) \leq \bar{i}_{j}, \quad \underline{i}_{S C} \leq i_{S C}(t) \leq \bar{i}_{S C} \\
\underline{q}_{j} \leq q_{j}(t) \leq \bar{q}_{j}, \quad \underline{q}_{S C} \leq q_{S C}(t) \leq \bar{q}_{S C},
\end{gathered}
$$

where $j \in \mathcal{J}, \underline{x}$ represents the lower bound and $\bar{x}$ the upper bound of the variable $x$.

The third set of constraints - the balancing constraints enforces small variations in temperature $\left(T_{j}\right)$ and $\mathrm{SoC}$ within the battery pack. Note that large temperature and SoC unbalances result in uneven aging mechanisms, which in turn lead to a rise in cell-to-cell variations, aggravating the "weakest-cell problem' [37]. To mitigate this issue, the following balancing constraints are considered:

$$
\begin{aligned}
& \Delta q_{j}(t)=\left|q_{j}(t)-q_{a v g}(t)\right| \leq \overline{\Delta q}, \\
& \Delta T_{j}(t)=\left|T_{j}(t)-T_{a v g}(t)\right| \leq \overline{\Delta T},
\end{aligned}
$$

where $j \in \mathcal{J}, \overline{\Delta q}$ is the maximum allowed difference between module's $\operatorname{SoC}\left(q_{j}\right)$ and pack's average $\operatorname{SoC}\left(q_{\text {avg }}(t)=\right.$ 


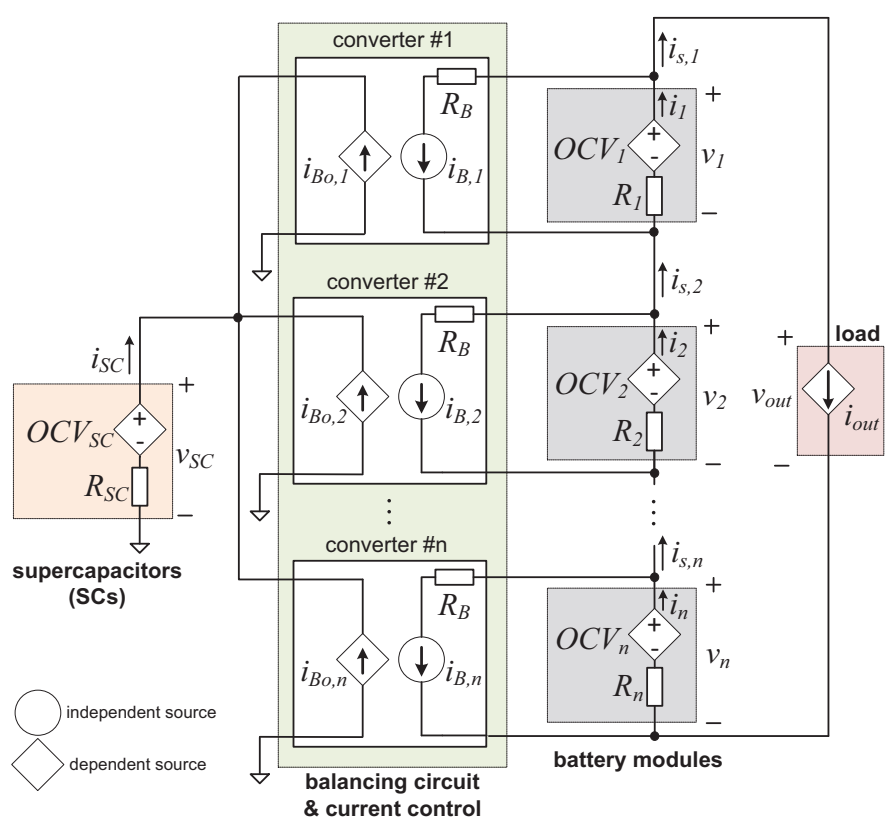

Fig. 3. Electric-equivalent circuit model of the hybrid balancing system, battery modules and SCs. Since the balancing currents $\left(i_{B, j}\right)$ are controlled variables of the power converters, they are represented through independent current sources. The output currents of the converters $\left(i_{B o, j}\right)$ and the vehicle load $\left(i_{\text {out }}\right)$ are formulated as dependent current sources; their value can be computed using the power balance relations (10), (18).

$\frac{1}{n} \sum_{j \in \mathcal{J}} q_{j}(t)$ ), while $\overline{\Delta T}$ represents the maximum difference between module's temperature $\left(T_{j}\right)$ and pack's average temperature $\left(T_{\text {avg }}(t)=\frac{1}{n} \sum_{j \in \mathcal{J}} T_{j}(t)\right)$. Perfect SoC and temperature equalization is obtained when $\Delta q_{j}=0$ and $\Delta T_{j}=0$, for all $j \in \mathcal{J}$.

In order to maximize the range of the vehicle, the energy management strategy focus on the minimization of energy losses $(L)$ of the HESS. Theses energy losses are generated by the SCs $\left(L_{S C}\right)$, battery modules $\left(L_{b a t}\right)$, and balancing circuit $\left(L_{b a l}\right)$ and are computed as:

$$
\begin{aligned}
L & =L_{S C}+L_{b a t}+L_{b a l} \\
& =\int_{0}^{t_{\text {end }}}\left(p_{l, S C}(t)+\sum_{j \in \mathcal{J}} p_{l, j}(t) \sum_{j \in \mathcal{J}} p_{l B, j}(t)\right) d t
\end{aligned}
$$

where $p_{l, S C}, p_{l, j}, p_{l B, j}$ are the power losses of SCs, battery modules and balancing circuits, respectively; $t_{\text {end }}$ is the duration of the vehicle's mission. Additionally, the total power provided by the HESS must match the load power $\left(p_{\text {out }}\right)$ requested by the vehicle's driveline.

Based on these elements, the energy management and battery balancing problem for the SHBS can be summarized as:

Problem 1. Find the reference values for the balancing currents, $i_{B, j}^{*}(t), j \in \mathcal{J}$, such that the energy losses $L$ are minimized, while complying with physical, safety and balancing constraints (1)-(3), and fulfilling the load power $p_{\text {out }}(t), t \in\left[0, t_{\text {end }}\right]$.

\section{Modeling And Optimal Control}

This section presents the control-oriented models of the hybrid energy storage units and power converters, as well as a convex optimization method to tackle Problem 1.

\section{A. Modeling}

1) Battery and Supercapacitor: Problem 1 presupposes the modeling of a string of $n$ battery modules. Since $n$ might be very large, the use of high-fidelity and dynamic battery models might lead to a complex balancing optimization problem. To avoid this hurdle, numerically efficient models - composed of an open-circuit voltage $O C V_{j}$ in series with an internal resistance $R_{j}$ - are used for both battery modules and SCs (see Fig. 3). Their terminal voltage $\left(v_{j}\right)$ and $\mathrm{SoC}\left(q_{j}\right)$ is given by:

$$
\begin{aligned}
& v_{j}(t)=O C V_{j}\left(q_{j}(t)\right)-R_{j} i_{j}(t), \\
& \dot{q}_{j}(t)=-\frac{1}{\bar{Q}_{j}} i_{j}(t),
\end{aligned}
$$

where $j \in \mathcal{J} \cup\{S C\}=\{1, \ldots, n, S C\}, \bar{Q}_{j}$ [As] is the nominal capacity, and $R_{j}[\Omega]$ is the cell's inner resistance. To simplify the notation, the SCs pack is treated as the $n+1$ module of the energy storage system.

The open-circuit voltage $O C V_{j}$ of the battery modules is approximated here as an affine mapping, dependent on the SoC [4], [19], [20]. It is described by the relation:

$$
O C V_{j}\left(q_{j}(t)\right)=a_{j}+b_{j} q_{j}(t)
$$

where $j \in \mathcal{J}, a_{j}[\mathrm{~V}]$ is the open-circuit voltage when the module is fully discharged, and $b_{j}[\mathrm{~V}]$ is the $\mathrm{SoC}$ gain. To represent the open-circuit voltage of the SCs $\left(O C V_{S C}\right)$, we exploit the definition of the SCs capacitance $\left(C_{S C}\right)$, which yields:

$$
O C V_{S C}\left(q_{S C}(t)\right)=\frac{\bar{Q}_{S C}}{C_{S C}} q_{S C}(t)=a_{S C}+b_{S C} q_{S C}(t)
$$

where $a_{S C}=0 \mathrm{~V}$ is the voltage offset and $b_{S C}=\bar{Q}_{S C} / C_{S C}$ [V] the SoC gain.

The thermal response of the battery modules relies on the model discussed in [11] and assumes: $i$ ) a lumped capacitance, ii) over-potential heating as the main source of heat generation, and iii) dissipation of heat due to conduction and convection. It is mathematically formulated as:

$$
\begin{aligned}
C_{h, j} \dot{T}_{j}(t) & =p_{l, j}(t)-\dot{Q}_{c n d, j}-\dot{Q}_{c n v, j}, \\
\dot{Q}_{c n v, j}(t) & =\left(T_{j}(t)-T_{e n v}\right) / R_{c o v}, \\
\dot{Q}_{c n d, j}(t) & =\left(2 T_{j}(t)-T_{j+1}(t)-T_{j-1}(t)\right) / R_{c n d},
\end{aligned}
$$

where $j \in \mathcal{J}, T_{j}[\mathrm{~K}]$ is the temperature in the battery modules, $T_{e n v}[\mathrm{~K}]$ is the environment temperature, and $C_{h, j}$ $[\mathrm{J} / \mathrm{K}]$ is the thermal capacitance. The heat generated by battery module is captured by $p_{l, j}[\mathrm{~J} / \mathrm{s}]$, i.e. internal power losses. The term $\dot{Q}_{c n d, j}[\mathrm{~J} / \mathrm{s}]$ represents the conductive heat flow between neighboring modules, while $\dot{Q}_{c n v, j}[\mathrm{~J} / \mathrm{s}]$ is the convective heat flow between battery modules and the environment. To better understand this formulation, Fig. 4 represents the thermal model though an electric-equivalent circuit. In this circuit, 


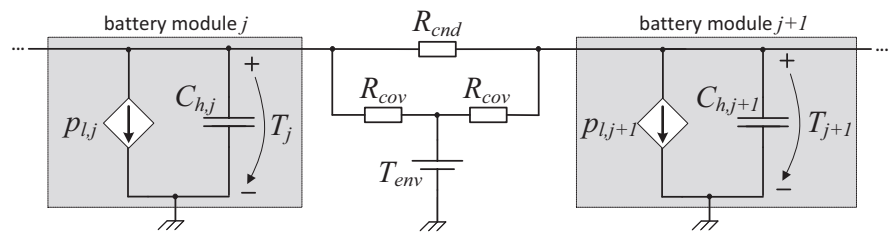

Fig. 4. Electric-equivalent circuit model for the thermal response of the battery modules.

temperatures in the battery modules and in the environment are equivalent to voltages, while heat flows are translated to currents. The heat flow is further dependent on the thermal resistance between neighboring modules $\left(R_{c n d}[\mathrm{~K} / \mathrm{W}]\right)$ and convective thermal resistance $\left(R_{\text {cov }}=1 /\left(h A_{j}\right) \quad[\mathrm{K} / \mathrm{W}]\right)$. The value of this last resistance is affected by the external surface area $\left(A_{j}\left[\mathrm{~m}^{2}\right]\right)$ and the convective heat transfer coefficient between the battery's external surface and environment $\left(h\left[\mathrm{~W} /\left(\mathrm{K} \cdot \mathrm{m}^{2}\right)\right]\right)$. The thermal response of the SCs, due to their high energy efficiency and good thermal properties, is not considered in this study.

2) Balancing circuit \& current control: The power converters embedded in the balancing circuit are approximated here as ideal dc-dc transformers with power losses. This means the power extracted from the battery side $\left(v_{j} i_{B, j}\right)$ must be transferred to the SCs bank $\left(v_{S C} i_{B o, j}\right)$ and cover the converter's power losses $\left(p_{l B, j}\right)$. The corresponding power balance relation for each converter is given by:

$$
v_{j}(t) i_{B, j}(t)=v_{S C}(t) i_{B o, j}(t)+p_{l B, j}(t),
$$

where $j \in \mathcal{J}$.

To assist in the regulation of the power flow within the dc-dc converters, current control loops, capable of tracking reference balancing currents $\left(i_{B, j}^{*}\right)$, are employed. These current loops usually have a very fast dynamic response - in the order of microseconds [38]. Since the dynamics relevant for the energy management and battery balancing functions are usually much slower (with typical samples times of 1s [4], [11]), this work neglects the transient response of the current loop, i.e., $i_{B, j}^{*} \approx$ $i_{B, j}$.

Additionally, Kirchhoff's current law can be applied to the nodes linking the power converters' primaries and secondary sides. This allow us to related the SCs currents $\left(i_{S C}\right)$ and the output currents of the converters $\left(i_{B o, j}\right)-$ in the secondary side - as well as the currents in the balancing circuit, battery module modules and battery pack $\left(i_{s, j}\right)$ - in the primary side. This leads to:

$$
\begin{aligned}
i_{j}(t) & =i_{B, j}(t)+i_{s, j}(t), \quad j \in \mathcal{J}, \\
i_{S C}(t) & =-\sum_{j=1}^{n} i_{B o, j}(t),
\end{aligned}
$$

3) Power Losses: To facilitate the formulation of optimization problem, we assume that the losses in the energy storage units $\left(p_{l, j}\right)$ and balancing circuits $\left(p_{l B, j}\right)$ can be lumped together into equivalent resistive components:

$$
\begin{aligned}
p_{l, j}(t) & =R_{j} i_{j}^{2}(t), \\
p_{l B, j}(t) & =R_{B} i_{B, j}^{2}(t)
\end{aligned}
$$

TABLE I

PARAMETERS OF THE SHBS

\begin{tabular}{cccc}
\hline Variable & Symbol & Value & Unit \\
\hline Battery cell & & & \\
Nominal voltage & $v_{b a t}$ & 3.6 & $\mathrm{~V}$ \\
Nominal capacity & $\bar{Q}_{b a t}$ & 3 & $\mathrm{~A} . \mathrm{h}$ \\
Internal resistance & $R_{b a t}$ & 51.16 & $\mathrm{~m} \Omega$ \\
min. OCV voltage & $a_{j}$ & 3.21 & $\mathrm{~V}$ \\
OCV gain & $b_{j}$ & 0.43 & $\mathrm{~V}$ \\
SoC limits & {$[\underline{q}, \bar{q}]$} & {$[0.05,0.95]$} & - \\
Current limits & {$[\underline{i}, \bar{i}]$} & {$[-4,20]$} & $\mathrm{A}$ \\
Voltage limits & {$[\underline{v}, \bar{v}]$} & {$[2.5,4.2]$} & $\mathrm{V}$ \\
Thermal capacitance & $C_{h}$ & 40.23 & $\mathrm{~J} / \mathrm{K}$ \\
External surface area & $A$ & 0.0042 & $\mathrm{~m}{ }^{2}$ \\
\hline Battery pack properties & & & \\
Stored energy & - & $10 \times 10.8$ & $\mathrm{Wh}$ \\
Conv. heat transfer coefficient & $h$ & 5.8 & $\mathrm{~W} /\left(\mathrm{K} . \mathrm{m}^{2}\right)$ \\
Thermal resistance & $R_{c n d}$ & 26.6 & $\mathrm{~K} / \mathrm{W}$ \\
Environment temperature & $T_{e n v}$ & 25 & ${ }^{\circ} \mathrm{C}$ \\
\hline SC pack properties & & & \\
Stored energy & - & $4 \times 0.31$ & $\mathrm{Wh}$ \\
Nominal voltage & $\bar{v}_{S C}$ & $4 \times 2.7$ & $\mathrm{~V}$ \\
Nominal capacity & $\bar{Q}_{S C}$ & 0.2325 & $\mathrm{~A} . \mathrm{h}$ \\
Capacitance & $C_{S C}$ & $310 / 4$ & $\mathrm{~F}$ \\
Internal resistance & $R_{S C}$ & $4 \times 2.2$ & $\mathrm{~m} \Omega$ \\
SoC limits & {$\left[\underline{q}_{S C}, \bar{q}_{S C}\right]$} & {$[0.5,1]$} & - \\
Current limits & {$\left[\underline{i}_{S C}, \bar{i}_{S C}\right]$} & {$[-250,250]$} & $\mathrm{A}$ \\
\hline Balancing constraints & $\bar{\Delta}_{q}$ & & \\
SoC operating window & $\bar{\Delta}_{\Delta}$ & 0.03 & - \\
Temp. operating window & {$\left[\underline{i}_{B}, \bar{i}_{B}\right]$} & {$[-4.5,4.5]$} & $\mathrm{A}$ \\
Balancing current limits & & &
\end{tabular}

where $R_{B}[\mathrm{~W}]$ is an equivalent resistance that captures the dominant losses in the dc-dc converters.

4) Vehicle Load: The energy storage units must deliver power $p_{\text {out }}(t)$ to the vehicle's driveline, i.e., the load block represented in Fig. 3. As discussed in [15], this load power depends on several factors, including the reference driving cycle, energy efficiency of the driveline's components (electric motor, inverter, mechanical transmission, etc), as well inertial, rolling and aerodynamic resistance forces. Since the focus of this work lies in the design and operation of the hybrid balancing circuit, the load power $p_{\text {out }}(t)$ is treated here as a known exogenous input.

Fig. 3 also shows that the load is coupled in parallel with the battery modules. The load voltage $v_{\text {out }}$ (summation of the battery module voltages), the load current $\left(i_{\text {out }}\right)$ and the battery pack current $\left(i_{s, j}\right)$ can be computed through direct application of Kirchhoff's current and voltage laws:

$$
\begin{aligned}
v_{\text {out }}(t) & =\sum_{j=1}^{n} v_{j}(t) . \\
i_{\text {out }}(t) & =i_{s, 1}(t), \\
i_{s, j}(t) & =i_{s, j+1}(t), \quad j \in\{1, \ldots, n-1\}, \\
p_{\text {out }}(t) & =v_{\text {out }}(t) i_{\text {out }}(t),
\end{aligned}
$$

For notation compactness, in what follows, we aggregate the problem variables into the vector

$$
\mathbf{z}(t)=\left[\mathbf{i}_{B}(t) \mathbf{q}(t) \mathbf{T}(t) \mathbf{i}(t) \mathbf{v}(t) \mathbf{i}_{s}(t) \mathbf{i}_{B o}(t)\right]
$$

Variables in bold, such as $\mathbf{i}_{B}$, contain the vectorial representation of a given quantity for the entire battery/SC pack, e.g., 
$\mathbf{i}_{B}=\left[i_{B, 1} \ldots i_{B, n}\right]^{T}$. The parameters of the model are shown in Table I.

\section{B. Convex Optimization}

The energy management and battery balancing tasks, formulated in Problem 1, can be translated into the following non-linear optimization formulation:

$$
\mathbf{z}^{*}(t)=\underset{\mathbf{z}(t)}{\arg \min } L \quad \text { s.t. (1) }-(3),(5)-(18) .
$$

The constraints of this problem are based on the safety and balancing constraints (1)-(3), as well as the differentialalgebraic equations associated with the control-oriented models of the balancing circuit and storage units, (5)-(18). Because some of these constraints are non-convex - e.g. non-affine equalities (13),(18) - finding unique optimal solutions for the above problem is a challenging task. To overcome this issue, pragmatic convex approximations - based on change of variables and constraints' relaxations [11], [39] - are pursued in this work. Due to space constraints, only a short summary of these approximations is provided.

The first step in the convexification process is the change of variable. We consider the accumulated energy $E_{j}$, powers $p_{j}, p_{s, j}, p_{B, j}$, and power losses $p_{l, j}, p_{l B, j}$ as new variables in the problem, which leads to the following transformation:

$$
\boldsymbol{\phi}_{j}=\left[\begin{array}{c}
E_{j} \\
T_{j} \\
p_{j} \\
p_{s, j} \\
p_{B_{j}} \\
p_{l, j} \\
p_{l B, j}
\end{array}\right] \triangleq \mathbf{g}_{j}(\mathbf{z})=\left[\begin{array}{c}
\frac{1}{2} C_{j}\left(a_{j}+b_{j} q_{j}(t)\right)^{2}-E_{0 j} \\
T_{j} \\
\left(a_{j}+b_{j} q_{j}(t)\right) i_{j}(t) \\
\left(a_{j}+b_{j} q_{j}(t)\right) i_{s, j}(t) \\
\left(a_{j}+b_{j} q_{j}(t)\right) i_{B, j}(t) \\
R_{j} i_{j}^{2}(t) \\
R_{B} i_{B, j}^{2}(t)
\end{array}\right],
$$

where $\phi_{j}$ aggregates the new dependent variables, $E_{0 c}=$ $\frac{1}{2} C_{j} O C V_{j}^{2}\left(q_{j}(0)\right)[\mathrm{J}]$ is the module's initial energy, $p_{j}[\mathrm{~W}]$ the internal power of the module and $C_{j}=\bar{Q}_{j} / b_{j}[\mathrm{~F}]$ a constant. Applying this change of variable to (5) - (18), allows us, for example, to replace the $\mathrm{SoC}$ dynamics (6) with an equivalent energy dynamics (20) and re-write the energy losses as a quadratic-over-affine function (21), dependent on $p_{j}$ and $E_{j}$.

$$
\begin{aligned}
\dot{E}_{j}(t) & =-p_{j}(t), \\
p_{l, j} & =\frac{R_{j} C_{j} p_{j}^{2}(t)}{2\left(E_{j}(t)+E_{0, j}\right)} .
\end{aligned}
$$

In the second step, non-convex equality constraints are relaxed into convex inequalities. This is performed, e.g., by approximating (21) with the convex inequality:

$$
p_{l, j} \geq \frac{R_{j} C_{j} p_{j}^{2}(t)}{2\left(E_{j}(t)+E_{0, j}\right)} .
$$

As discussed in [39], this relaxation is motivated by the inclusion of $p_{l, j}$ in the cost function $L$, which incentivizes the numerical solver to minimize the power losses and approach the lower bound (22). Similar approximations can be performed for the power losses due to balancing current $\left(p_{l B, j}\right)$ and battery pack current $\left(p_{l s, j}=R_{j} i_{s, j}^{2}\right)$, as shown in Table II (rows $4 c$ and $4 d$ ).
TABLE II

CONVEX FORMULATION FOR THE ENERGY MANAGEMENT AND BATTERY BALANCING PROBLEM

$$
\begin{aligned}
& \text { Variables: } E_{j}, T_{j}, p_{j}, p_{s, j}, p_{B, j}, p_{l, j}, p_{l B, j} \\
& \text { Objective: }^{(\mathrm{A} 0)} \\
& \min \cdot \underbrace{\sum_{k=0}^{N_{t}}\left(p_{l, S C}[k]+\sum_{j \in \mathcal{J}} p_{l, j}[k]+p_{l B, j}[k]\right) \Delta t}_{\approx L}+\theta \sum_{k=0}^{N_{t}} p_{l s, j}[k] \Delta t
\end{aligned}
$$

\section{Constraints:}

Safety constraints

$$
\begin{aligned}
1 a: & p_{l B, j}[k] \leq R_{B}\left(\bar{i}_{B}\right)^{2}, \quad j \in \mathcal{J}, \\
1 b: & \underline{i}_{j} \sqrt{\frac{2}{C_{j}}\left(E_{j}[k]+E_{0 j}\right)} \leq p_{j}[k] \leq \bar{i}_{j} \sqrt{\frac{2}{C_{j}}\left(E_{j}[k]+E_{0 j}\right),} \\
1 c: & \frac{C_{j} O C V_{j}^{2}\left(\underline{q}_{j}\right)}{2} \leq E_{j}[k]+E_{0 j} \leq \frac{C_{j} O C V_{j}^{2}\left(\bar{q}_{j}\right)}{2}, \\
& j \in \mathcal{J} \cup\{S C\},
\end{aligned}
$$

Balancing constraints

$$
\begin{aligned}
& 2 a:\left|\frac{2}{C_{j}} E_{j}[k]-\frac{1}{n} \sum_{l=1}^{n} \frac{2}{C_{l}} E_{l}[k]\right| \leq\left(a_{j}+b_{j} \overline{\Delta q}\right)^{2}-a_{j}^{2}, \\
& 2 b:\left|T_{j}[k]-\frac{1}{n} \sum_{l=1}^{n} T_{l}[k]\right| \leq \overline{\Delta T}, \quad j \in \mathcal{J},
\end{aligned}
$$

Thermal model

$$
\begin{aligned}
3: & C_{h, j}\left(T_{j}[k+1]-T_{j}[k]\right) \frac{1}{\Delta t}=p_{l, j}[k]- \\
& \left(T_{j}(t)-T_{\text {env }}\right) / R_{\text {cov }}-\left(2 T_{j}[k]-T_{j+1}[k]-T_{j-1}[k]\right) / R_{c n d},
\end{aligned}
$$

Energy storage and power balance ${ }^{(\mathrm{A} 1)}$

$4 a: E_{j}[k+1]-E_{j}[k]=-p_{j}[k] \Delta t$,

$4 b: p_{l, j}[k] \geq \frac{R_{j} C_{j} p_{j}^{2}[k]}{2\left(E_{j}[k]+E_{0 j}\right)}, \quad j \in \mathcal{J} \cup\{S C\}$,

$4 c: p_{l B, j}[k] \geq \frac{R_{B} C_{j} p_{B, j}{ }^{2}[k]}{2\left(E_{j}[k]+E_{0 j}\right)}$,

$$
4 d: p_{l s, j}[k] \geq \frac{R_{j} C_{j} p_{s, j}^{2}[k]}{2\left(E_{j}[k]+E_{0 j}\right)},
$$$$
4 e: p_{\text {out }}[k]=\sum_{j=1}^{n}\left(p_{j}[k]-p_{l, j}[k]-p_{l B, j}[k]\right)+p_{S C}[k]-p_{l, S C}[k],
$$

$4 f: p_{j}[k]=p_{s, j}[k]+p_{B, j}[k]$,

$4 g: p_{s, j}[k]=p_{s, j+1}[k]$,

$$
\begin{aligned}
4 h: \sum_{j=1}^{n}\left(p_{B, j}[k]-p_{l B, j}[k]-\frac{1}{2}\left(p_{l, j}[k]+\frac{R_{j}}{R_{B}} p_{l B, j}[k]-p_{l s, j}[k]\right)\right) & \\
& =-\left(p_{S C}[k]-p_{l, S C}[k]\right), \\
j \in \mathcal{J}, k & \in\left\{0, \ldots, N_{t}\right\}
\end{aligned}
$$

(A0) first component of the cost function represents the discrete approximation of the energy losses $L$; the second component is a penalization term to incentivize the numerical solver to search for $p_{l s, j}$ closer to the lower bound defined in constraint $4 d$ (note: $\theta$ is a weight).

(A1) constraint $4 g$ approximates (17) under the assumption that SoC deviations are small, which is justified due to equalization constraint (3a); derivation of constraint $4 h$ requires extensive algebraic manipulations (see [11, Appendix B]).

In the third and last step, the differential equations and cost function are discretized with the forward Euler method using the sample time $\Delta t=1 \mathrm{~s}$ and $N_{t}$ sample points. The resulting optimal problem is described in Table II. This problem is convex because [32]: $i$ ) the cost function is linear, $i i$ ) all equality constraints are affine in the decision variables, $i i i)$ the inequalities are either linear (e.g. rows $1 a, 1 c, 2$, etc) 
or convex non-linear (e.g., rows $1 b, 4 b$, etc). To solve this optimal control problem, we employed the parser CVX [40] - a modeling framework for convex optimization - and the numerical solver SPDT3 [41]. Finally, after computing the optimal solution, the balancing currents can be obtained by inverting transformation (19).

The dimension of the optimal problem described in Table II scales with the number of battery modules, i.e., large battery packs -with dozens of battery modules- induce a large-scale convex optimization problem. This increases computational complexity and complicates the online implementation in embedded control systems. Consequently, the convex problem presented in Table II should be seen as an offline benchmark method to compute the theoretical optimum solution for the SHBS. The development of online variants for this problem, e.g. with linear [3] or quadratic [32] programming methods, will be tackled in future works.

\section{EXPERIMENTAL PROTOTYPE}

To validate the SHBS concept, a small-scale prototype was built. As depicted in Fig. 5a, this prototype has four main components: $i$ ) hybrid energy storage unit (batteries and SCs), ii) balancing circuit, iii) control unit and $i v$ ) load emulation.

\section{A. Hybrid Energy Storage Unit}

The hybrid energy storage is composed of 4 SCs (Maxwell BCAP0310 P270 T10) and 10 batteries cells (cylindrical Liion, LG 18650HG2). The SCs are connected in series, while the battery cells are divided in a string of 3 modules. As shown in Fig. 5c, the first battery module contains 4 battery cells, connected in parallel, while the second and third have 3 battery cells, also coupled in parallel. The goal of this configuration is to artificially emulate imbalances in capacity, inner impedance and thermal properties of the battery pack, which might appear due to aging of the cells. As a result of this battery arrangement, module \#1 has $25 \%$ higher capacity and $33 \%$ lower inner resistance than modules \#2 and \#3, i.e.,

$$
\begin{aligned}
{\left[R_{1}, R_{2}, R_{3}\right] } & =\left[R_{b a t} / 4, R_{b a t} / 3, R_{b a t} / 3\right] \\
{\left[\bar{Q}_{1}, \bar{Q}_{2}, \bar{Q}_{3}\right] } & =\left[4 \bar{Q}_{b a t}, 3 \bar{Q}_{b a t}, 3 \bar{Q}_{b a t}\right]
\end{aligned}
$$

where $R_{b a t}$ and $\bar{Q}_{b a t}$ are the nominal inner resistance and capacity of the battery cells, respectively. The remaining parameters of the battery cells and SCs are shown in Table I.

\section{B. Balancing Circuit and Current Control}

For the implementation of the balancing circuit, a dual half bridge (DHB) topology was selected. The DHB, depicted in Fig. 5b, is particularly attractive for the SHBS application because it offers low current ripple, isolated operation and bidirectional flow of power between the battery modules and the SCs [42]. The control of the balancing current $\left(i_{B, j}\right)$ is based on phase-shift and proportional and integral (PID) control action, which is implemented in an embedded control system (TI TMS320F28377S microprocessor); further details on the control of the balancing circuit can be found in [38].

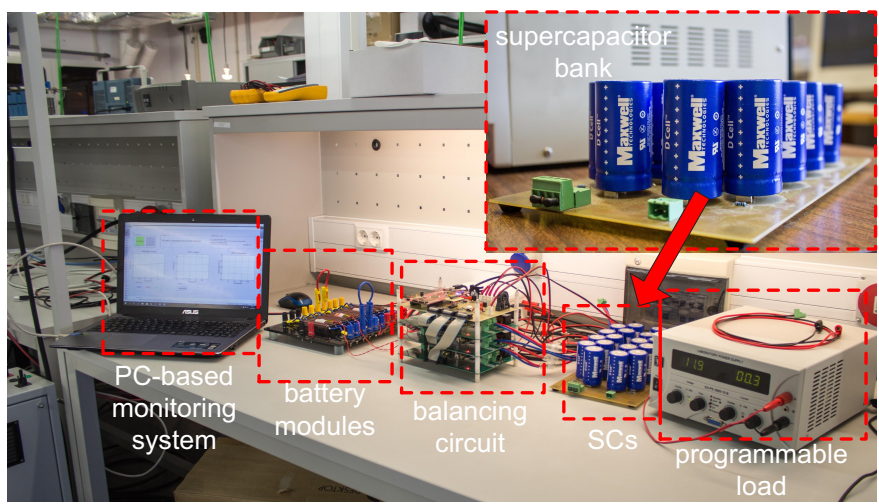

(a) experimental setup

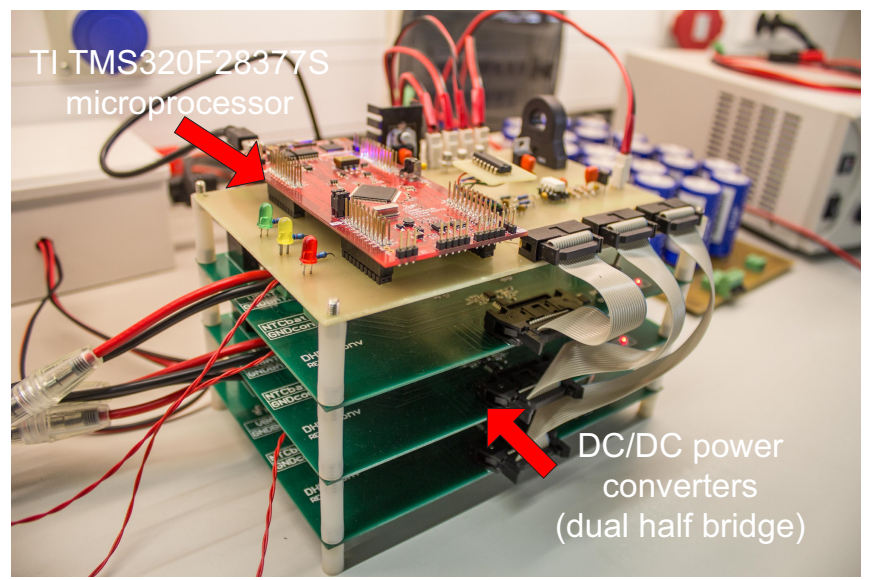

(b) detailed view of the balancing circuit

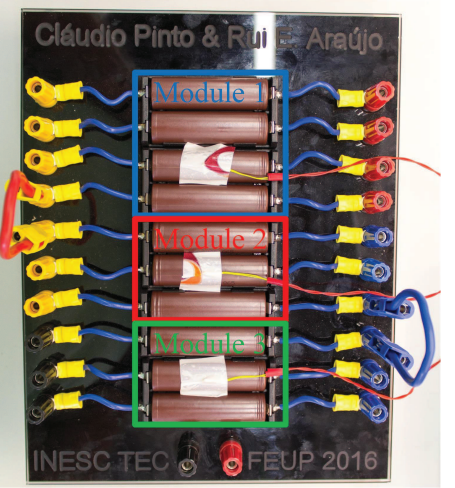

(c) battery modules

Fig. 5. Small-scale prototype of the SHBS.

As previously mentioned, we assume that the vehicle power profile and status of the battery modules (i.e. SoC) are known at the beginning of the journey. Based on this information, the optimal current setpoints $i_{B, j}^{*}$ for the balancing circuit can be computed offline (e.g. by solving the problem formulated in Table II at the beginning of the journey) and then stored in a look-up table inside the microprocessor.

A final note on the SCs pack. As with batteries, SCs are also affected by non-uniform characteristics, such as variances in capacitance, internal resistance and self-discharge rate. When interconnecting SCs in series, these non-uniform characteris- 

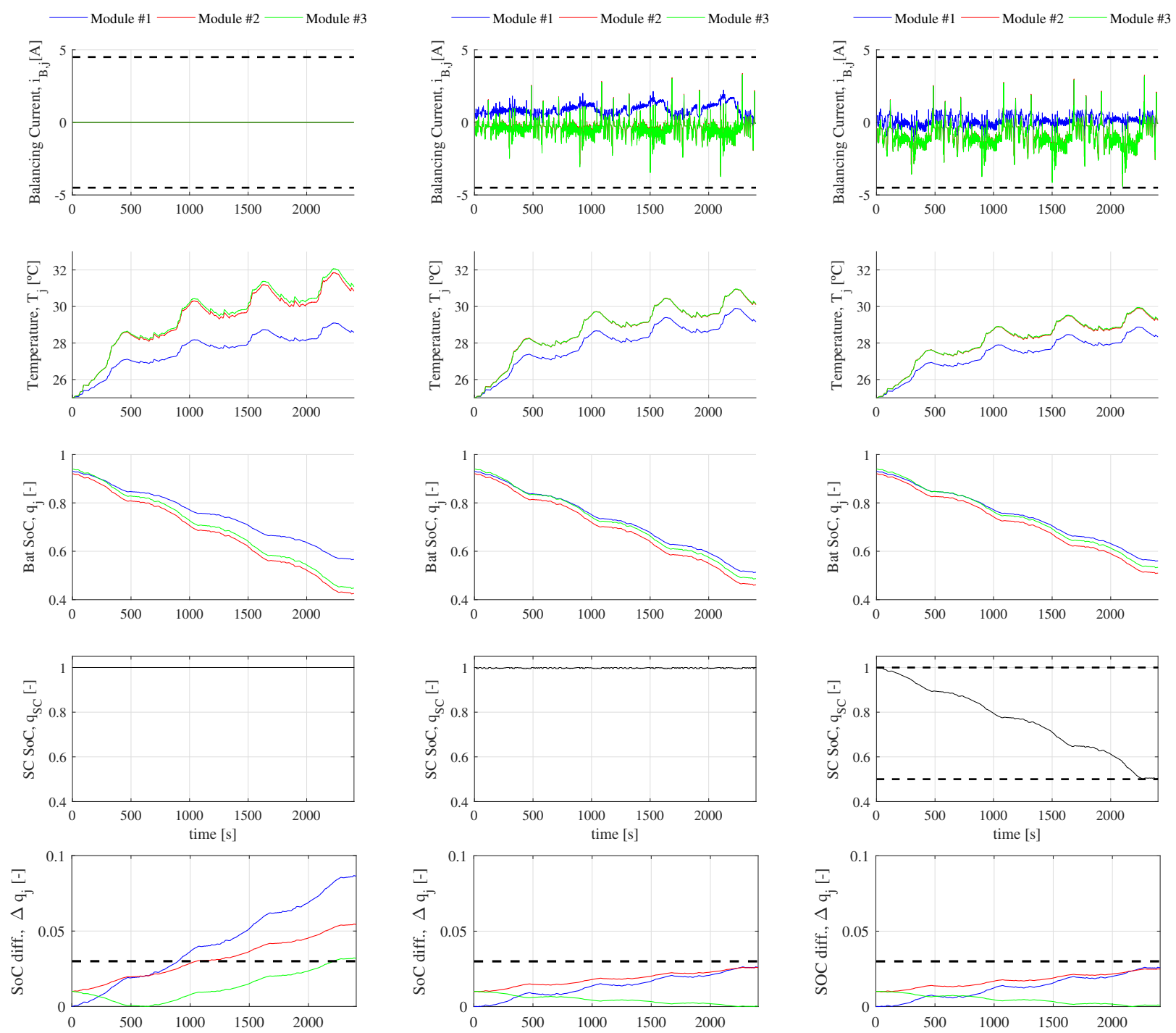

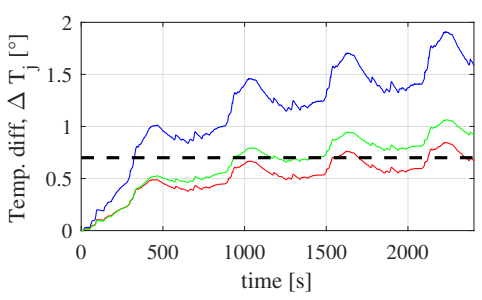

(a) NB

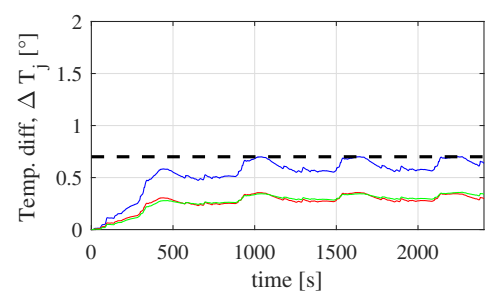

(b) SBS

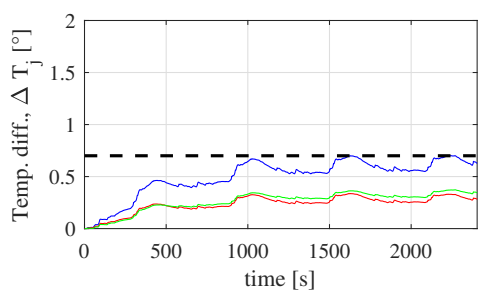

(c) SHBS

Fig. 6. Simulation results of different balancing configurations: a) no balancing, b) smart balancing system, c) smart and hybrid balancing system. Balancing constraints are depicted in dashed black lines.

tics might lead to unequal voltage distribution in the SCs pack and affect their reliability. To mitigate this issue, a passive resistor-based balancing circuit for the SCs -similar to the one described in [43]- was included in our small-scale prototype.

\section{Simulation Results}

This section presents the simulation results of the proposed hybrid balancing system. Besides the SHBS, two other variants are considered: $i$ ) no balancing (NB), which is obtained by disabling the balancing circuit $\left(i_{B, j}=0\right)$, and $\left.i i\right)$ smart balancing system (SBS), where the SCs bank operates as a small energy buffer. The SBS was obtained by solving the optimization problem described in Table II with the lower bound of the SCs SoC $\left(\underline{q}_{S C}\right)$ parameterized as

$$
\underline{q}_{S C}=\sigma \bar{q}_{S C}
$$

where $\sigma \in(0,1]$ is a constraint tightening factor that defines the range of SCs energy available to the SBS. In this work, a constraint tightening factor of $\sigma=0.995$ is considered, which forced the SBS to operate with very small variations in the SCs SoC. Additionally, to make a fair comparison between the balancing variants, the current limits of the 


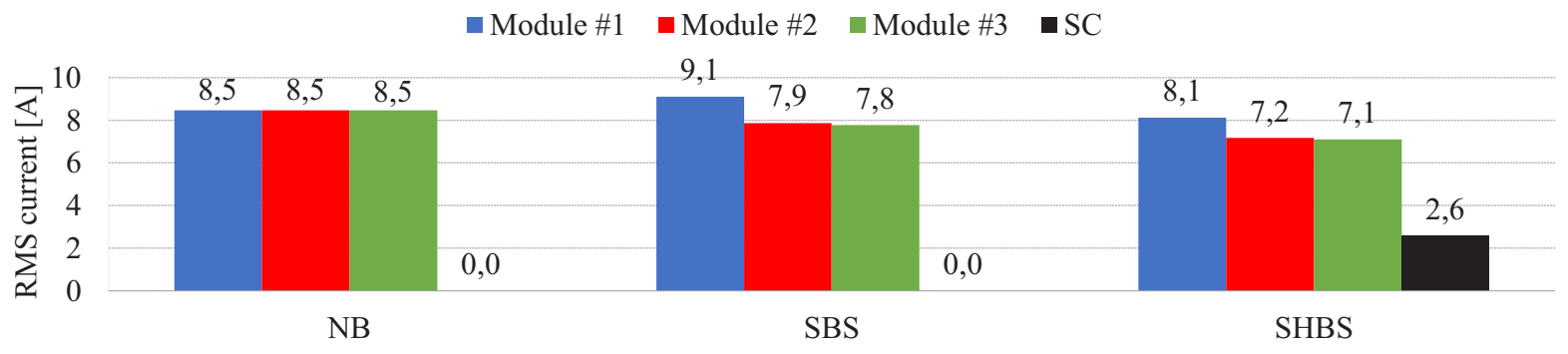

Fig. 7. RMS currents $\left(i_{j}^{r m s}\right)$ in the battery modules and SCs for different balancing configurations.
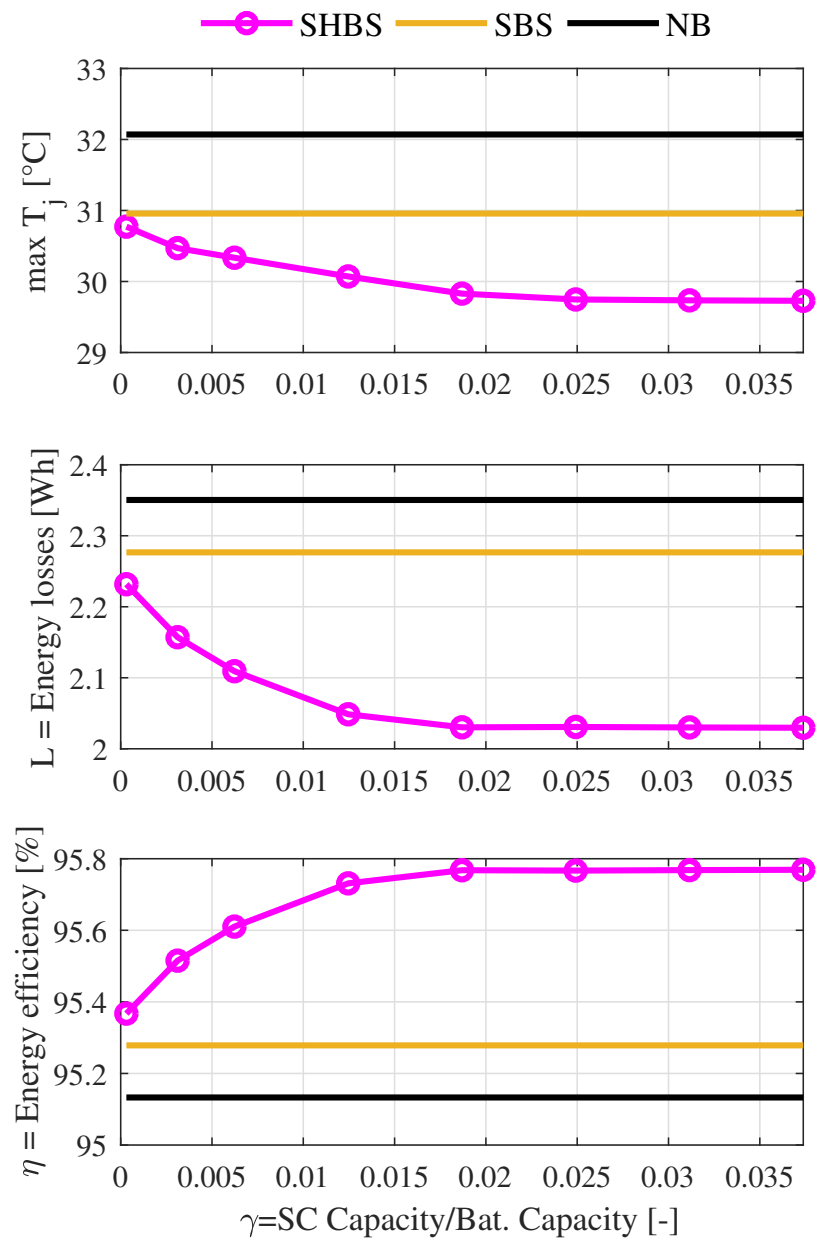

Fig. 8. Sensitivity analysis: effect of the hybridization ratio $\gamma$ in the energy losses $(L)$, maximum temperature in the battery modules and energy efficiency $(\eta)$, where $\eta=E_{\text {out }} /\left(L+E_{\text {out }}\right), \quad E_{\text {out }}=\int_{0}^{t_{\text {end }}} p_{\text {out }}(t) d t$. Note: the experimental results and numerical simulations employ a nominal hybridization ratio of $\gamma=0.008$.

power converters $(\underline{i}, \bar{i})$ are the same for both SBS and SHBS variants. This simulation study further considers that the power requested to the hybrid storage system, $p_{\text {out }}(t)$, follows a scaled version of the US06 driving cycle, repeated 4 times, and all battery modules have an initial SoC of $90 \%$. The remaining parameters of the system are present in Table I.

To quantify battery stress and degradation, the root-meansquare (RMS) value of the battery current $\left(i_{j}^{r m s}\right)$ is considered as an additional performance metric. Its value is determined as:

$$
i_{j}^{r m s}=\sqrt{\frac{1}{t_{\text {end }}} \int_{0}^{t_{\text {end }}} i_{j}^{2}(t) d t}, \quad j \in \mathcal{J}
$$

As discussed in [14], [16] lower current RMS values decrease heat, $\mathrm{SoC}$ variations and stress in the battery.

\section{A. Time-domain Results}

Fig. 6 depicts the time-domain results obtained for the three balancing configurations under investigation, while Fig. 7 provides the RMS value of the current in the battery modules. In the NB case (Fig. 6a), the current is equally distributed among the battery modules. This factor, together with the capacity imbalances in the battery modules, leads to a significant spread in temperature and SoC; for example, Fig. 6a shows SoC differences $\left(\Delta q_{j}\right)$ of up to $8 \%$ and temperature variations $\left(\Delta T_{j}\right)$ of $2^{\circ} \mathrm{C}$, which significantly violates the desired thermal and $\mathrm{SoC}$ equalization constraints. The weakest battery modules (\#2 and \#3) are particularly under stress. At the end of the driving cycle, modules \#2 and \#3 have a SoC of $42 \%-44 \%$, while module \#1 contains $56 \%$. This means that modules \#2 and \#3 will reach their SOC lower limits much earlier than module $\# 1$, constraining the power availability of the storage unit.

The results for the SBS can be seen in Fig. 6b. During the discharge phases, the SBS generates mainly positive balancing currents in module \#1, while modules \#2 and \#3 have predominantly negative balancing currents. This means that the SBS increases the current of the high-capacity module (\#1), while relieving the current load of the low-capacity modules $(\# 2, \# 3)$ - see also Fig. 7. As a result of this intervention, the SBS is able to enforce the SoC and thermal equalization constraints. At the end of the driving cycle the battery SOC lies in the interval $46-51 \%$ (i.e. the minimum SOC is increased by $4 \%$ when compared with $\mathrm{NB}$ ), while the thermal variation remains below $0.7^{\circ} \mathrm{C}$. One can also observe a reduction of $1^{\circ} \mathrm{C}$ in the peak temperature of the battery pack (in comparison with NB), which can be explained by the load reduction in the weaker modules (\#2 and \#3).

Fig. 6c depicts the results for the SHBS. Similarly to the SBS, the SHBS is also able to enforce SOC and thermal equalization constraints. However, due to inclusion of the auxiliary energy storage unit (SCs), there are differences in the energy re-distribution within the battery pack. In particular, note that the balancing current of module \#1 is close zero, while the balancing currents of modules \#2 and \#3 have predominantly 


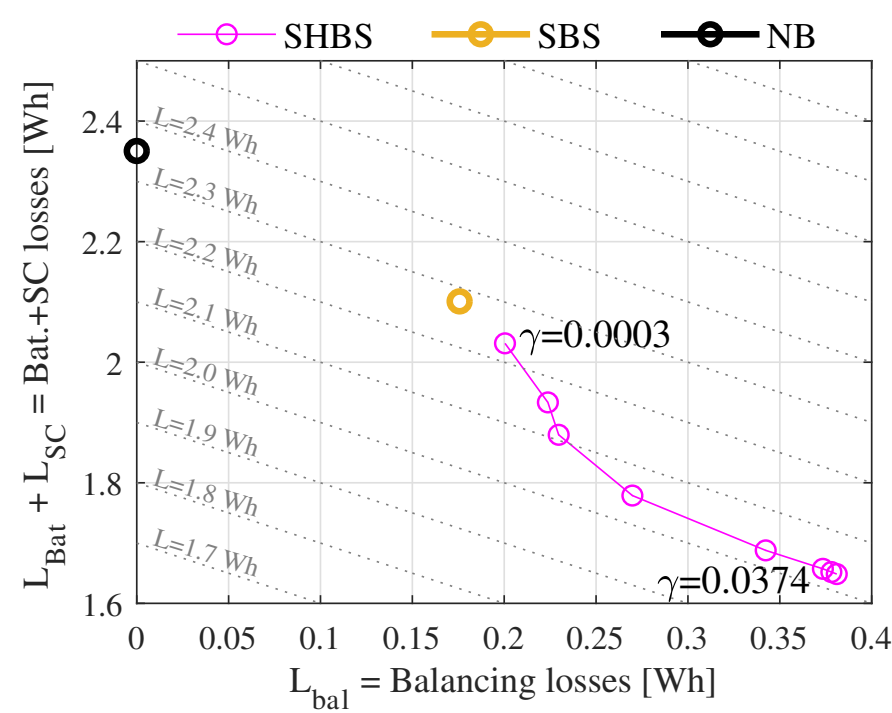

Fig. 9. Sensitivity analysis: effect of the hybridization ratio $\gamma$ in the energy storage losses $\left(L_{b a t}+L_{S C}\right)$, balancing losses $\left(L_{b a l}\right)$ and overall losses $(L)$.

negative currents. This means the SHBS exploits the auxiliary energy storage, the SCs, to decrease the current stress in the battery modules (see Fig. 7). The current in module \#1 is 8.1 A rms ( $-4.7 \%$ than NB and $-10 \%$ than SBS), while module \#2 and \#3 have a current of 7.2 A rms $(-15.2 \%$ than NB and $-8.8 \%$ than SBS). Additionally, the inclusion of the $\mathrm{SCs}$ contributes to a reduction in the maximum temperature of the batteries: $-1^{\circ} \mathrm{C}$ in comparison with SBS and $-2^{\circ} \mathrm{C}$ in comparison with NB. The SHBS also exhibits the highest battery $\mathrm{SoC}$ at the end of the driving cycle. In particular, the SHBS's minimum SoC is $2.5 \%$ higher than the SBS and $6.5 \%$ higher than the NB, which has a positive impact on the vehicle's range.

\section{B. Sensitivity to SCs capacity}

Let us now analyze in more detail the energy losses and efficiency of the different balancing strategies. In this analysis we also consider the effect of the SCs capacity in the energy performance; this variation is parameterized as $\bar{Q}_{S C}=\gamma \sum_{j \in \mathcal{J}} \bar{Q}_{j}$, where $\gamma>0$ represents a tunable hybridization ratio of the energy storage system.

The obtained results, depicted in Fig. 8, reveal that a moderate increase in the hybridization ratio $(\gamma \in[0.0003,0.02])$ has a positive impact in the energy losses $(L)$, maximum temperature, and energy efficiency, improving the performance of the SHBS over the baseline configurations SBS and NB. These positive impacts appear to saturate for higher values of hybridization ratio, indicating that the maximum benefit of the SHBS configuration is obtained when $\gamma \approx 0.02$. In comparison with the NB, the SHBS $(\gamma=0.02)$ is able to reduce the energy losses in $0.3 \mathrm{Wh}(-13 \%)$, the maximum temperature in $2.5^{\circ} \mathrm{C}$ $(-7.8 \%)$, while the energy efficiency is increased in $0.76 \%$.

Further insight into the SHBS performance limitations can be obtained by inspecting the two main sources of losses: $i)$ the energy storage losses $\left(L_{b a t}+L_{S C}\right)$, and $\left.i i\right)$ balancing losses $\left(L_{b a l}\right)$. Fig. 9 shows that higher hybridization ratios

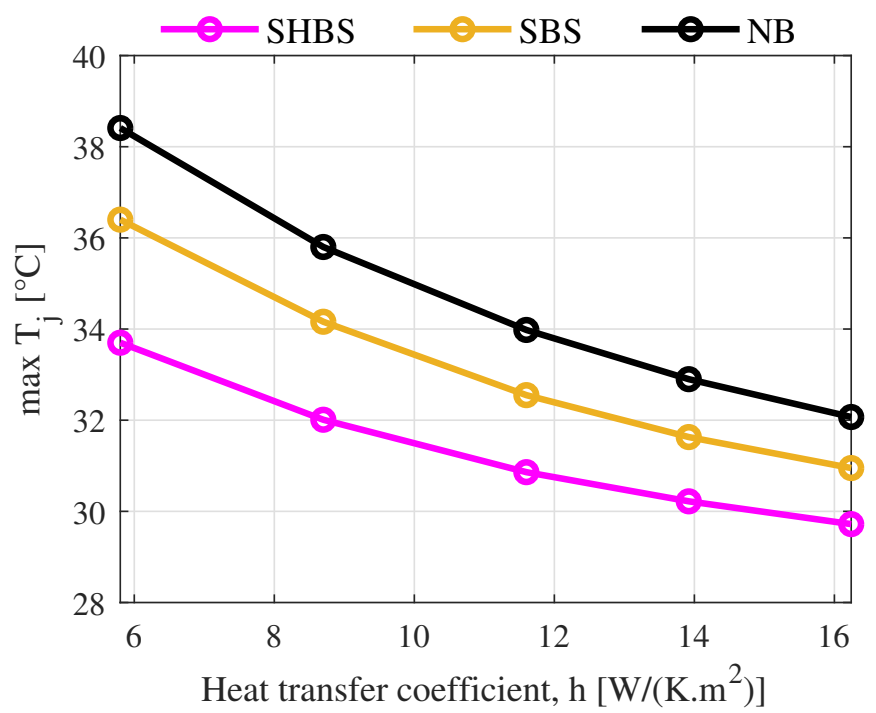

Fig. 10. Impact of the heat transfer coefficient in the maximum temperature of the battery modules.

contribute to a reduction in the energy storage losses; this can be justified by the greater usage of the SCs, which is the most efficient energy storage unit (note that $R_{S C} \ll R_{j}$ ). However, the higher usage of SCs also raises the energy losses in the balancing circuit, $L_{b a l}$, which offsets the overall energy gains and constraints the maximum benefits of the SHBS. This indicates that the SHBS indirectly transfers energy losses from the battery pack into the balancing system, which might facilitate the cooling of the batteries.

\section{Sensitivity to heat transfer coefficient}

To further investigate the impact of the cooling system within the balancing variants, a sensitivity analysis of the parameter $h$ - the heat transfer coefficient - is presented in Fig. 10. It can be seen that lower values of $h$ lead to an increase in the maximum temperature of the battery modules for all configurations; this can be explained by the reduced heat transfer rate (between battery's surface to the external environment) associated with lower values of $h$. The results also reveal that both the SHBS and SBS are able to decrease the maximal temperature in the battery pack; for example, considering $h=6 \mathrm{~W} /\left(\mathrm{K} \cdot \mathrm{m}^{2}\right)$, the SBS decreases the maximum temperature in $2^{\circ} \mathrm{C}$ in comparison with the NB variant, while the SHBS enables a $4.41^{\circ} \mathrm{C}$ reduction. These thermal gains can be particularly beneficial for battery packs with limited cooling. A SHBS-based battery pack with poor cooling $(h=6$ $\left.\mathrm{W} /\left(\mathrm{K} . \mathrm{m}^{2}\right)\right)$ provides similar peak temperatures $\left(33.8^{\circ} \mathrm{C}\right)$ as a battery pack with NB and good cooling $\left(h=13 \mathrm{~W} /\left(\mathrm{K} \cdot \mathrm{m}^{2}\right)\right)$ and an SBS with average cooling $\left(h=10.5 \mathrm{~W} /\left(\mathrm{K} . \mathrm{m}^{2}\right)\right)$. Thus, the introduction of the SHBS decreases the cooling needs of the battery pack, which might pave the way for a cost reduction in the cooling sub-system.

\section{EXPERIMENTAL VALIDATION}

To validate the feasibility of the proposed balancing system, experimental tests were carried out in the setup described in 

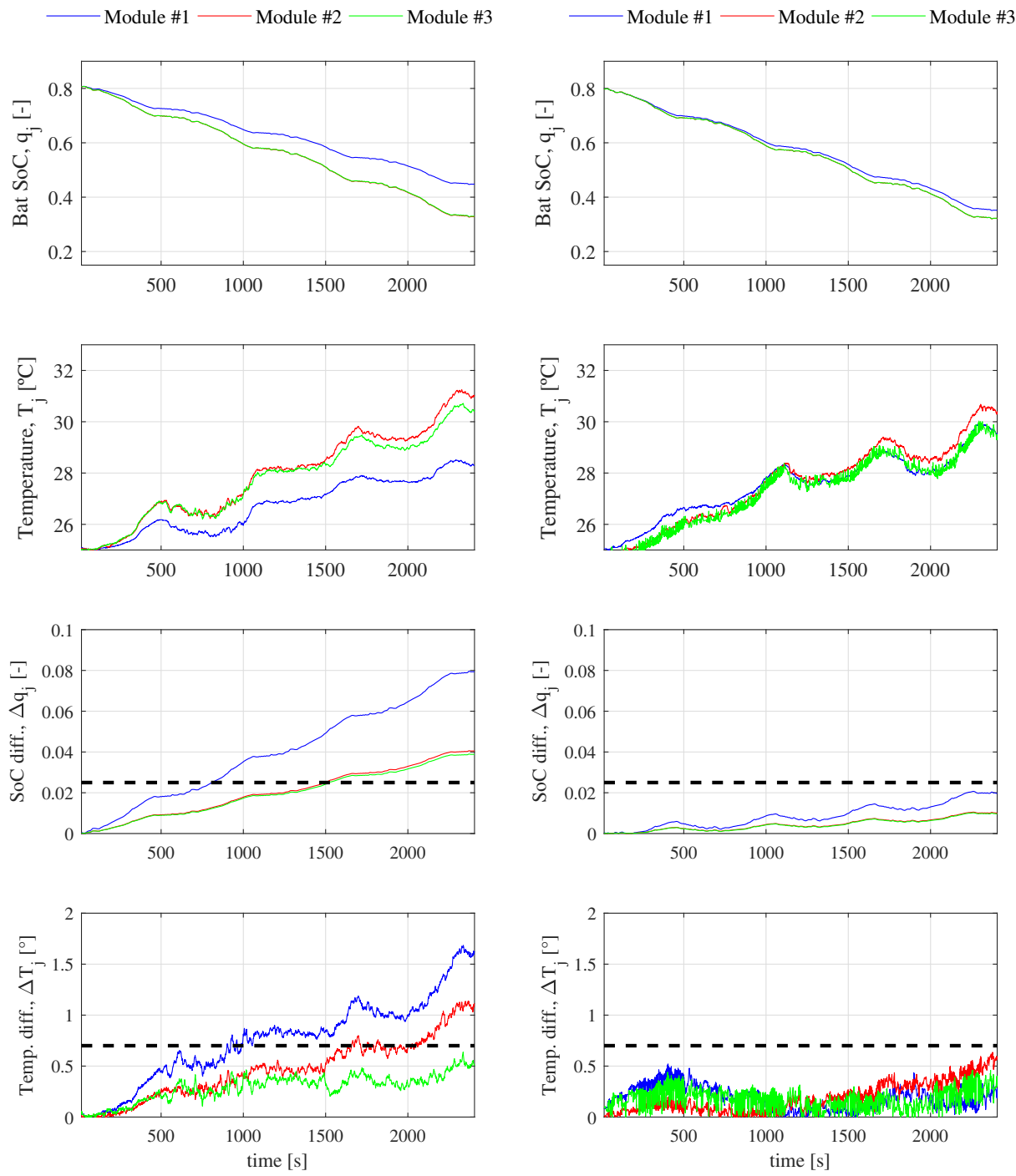

(a) NB

(b) SHBS

Fig. 11. Experimental results: a) no balancing; b) smart and hybrid balancing system.

Section IV. These experiments use the same driving cycle as the one employed in the previous section. Fig. 11 depicts the obtained experimental results for the SHBS and NB configurations. Overall, the experimental results are in accordance with the numerical simulations. In the NB configuration, significant spread in $\mathrm{SoC}$ (up to $8 \%$ ) and temperature (up to $1.8^{\circ} \mathrm{C}$ ) of the battery modules are observed. Battery modules \#2 and \#3 - the weaker modules with low-capacity and high inner resistance - suffer quicker discharge and higher temperatures. Conversely, the SHBS configuration (see Fig. 11b) is able to successfully enforce the $\mathrm{SoC}$ and thermal constraints, staying below the $3 \% \mathrm{SoC}$ difference and $0.7^{\circ} \mathrm{C}$ temperature difference thresholds; the peak temperature in the battery pack is also reduced from $31.2^{\circ} \mathrm{C}$ to $30.5^{\circ} \mathrm{C}$. These results demonstrates the feasibility of the SHBS energy redistribution policy to compensate capacity and thermal imbalances within the battery pack.

Despite these encouraging results, there is one limitation worth mentioning: the optimal control policy of the SHBS requires precise knowledge of the model parameters and disturbances. In the practical deployment of the control algorithm it might be difficult to fulfill this requirement. To mitigate this limitation, future works should enhance the SHBS with feedback control strategies (e.g. implement the optimal control policy in a receding horizon fashion [44]). Furthermore, to improve robustness of the optimal control policy against disturbances, one might also need to relax the $\mathrm{SoC}$ and temperature variations constraints (3) into soft constraints.

\section{CONCLUSIONS \& OUTLOOK}

This work investigated the possibility to jointly balance battery cells and perform hybridization of batteries with SCs. The proposed SHBS concept exploited the power converters embedded in the balancing system to provide SoC/temperature equalization and minimize the energy losses in the hybrid storage system. Pragmatic simplifications of the electric and thermal models were also employed, enabling the control of 
the SHBS trough a numerically-efficient convex optimization method. Simulation results showed that, in comparison with non-hybrid balancing configurations, the SHBS is able to:

- reduce the energy losses up to $13 \%$ and the maximum temperature up to $7.8 \%$, which has a positive impact on the vehicle's range and cooling needs

- decrease the current root-mean-square value in the battery cells up to $15 \%$, reducing its stress and degradation

- diminish the SoC and temperature variations within the battery pack, attenuating the effect of the weakest cell/module

Experimental results, obtained with a small scale prototype, further demonstrated the effectiveness and feasibility of the SHBS concept.

Despite these promising results, one important question remains open: are the SHBS advantages enough to offset its higher costs, volume, weight and complexity? The authors are optimistic about a positive answer to this question. The affordability and reliability of power electronics, necessary for the implementation of the balancing system, is continuously increasing. A new market for the second-life use of batteries in grid-support applications is also emerging, which is further encouraging a careful management of the battery cells during their first-life, within the electric vehicle. In our opinion, these trends will increase the competitiveness of the SHBS configurations in the near future, mitigating their higher initial costs. Nevertheless, further research is still needed to quantify costbenefits of the SHBS, e.g. through techno-economic analysis.

Future works should also tackle online control schemes for the SHBS. The convex optimization method employed in this work, despite providing unique optimal solutions, might require high computational effort, which complicates its implementation in embedded control systems with limited computational resources. To overcome this limitation, future research should focus on the development of lightweight optimization approaches, e.g. based on linear or quadratic optimization problems. Furthermore, to demonstrate feasibility of the SHBS for large battery packs, hardware-in-the-loop tests should also be performed.

\section{REFERENCES}

[1] J. Barreras, D. Frost, and D. Howey, "Smart Balancing Systems: An Ultimate Solution to the Weakest Cell Problem?" IEEE Vehicular Technology Society Newsletter, 2018.

[2] J. Gallardo-Lozano, E. Romero-Cadaval, M. I. Milanes-Montero, and M. A. Guerrero-Martinez, "Battery equalization active methods," Journal of Power Sources, vol. 246, pp. 934-949, Jan. 2014.

[3] R. Gu, a. P. Malysz, M. Preindl, H. Yang, and A. Emadi, "Linear programming based design and analysis of battery pack balancing topologies," in IEEE Transportation Electrification Conference and Expo (ITEC), Jun. 2015, pp. 1-7.

[4] F. Altaf, B. Egardt, and L. J. Mårdh, "Load Management of Modular Battery Using Model Predictive Control: Thermal and State-of-Charge Balancing," IEEE Transactions on Control Systems Technology, vol. 25, no. 1, pp. 47-62, Jan. 2017.

[5] J. V. Barreras, C. Pinto, R. d. Castro, E. Schaltz, S. J. Andreasen, and R. E. Araujo, "Multi-Objective Control of Balancing Systems for LiIon Battery Packs: A Paradigm Shift?" in 2014 IEEE Vehicle Power and Propulsion Conference (VPPC), Oct. 2014, pp. 1-7.

[6] L. McCurlie, M. Preindl, and A. Emadi, "Fast Model Predictive Control for Redistributive Lithium-Ion Battery Balancing," IEEE Transactions on Industrial Electronics, vol. 64, no. 2, pp. 1350-1357, Feb. 2017.
[7] D. F. Frost and D. A. Howey, "Completely Decentralized Active Balancing Battery Management System," IEEE Transactions on Power Electronics, vol. 33, no. 1, pp. 729-738, Jan. 2018.

[8] H. Rahimi-Eichi, U. Ojha, F. Baronti, and M.-Y. Chow, "Battery Management System: An Overview of Its Application in the Smart Grid and Electric Vehicles," IEEE Industrial Electronics Magazine, vol. 7, no. 2, pp. 4-16, Jun. 2013.

[9] M. Preindl, "A Battery Balancing Auxiliary Power Module With Predictive Control for Electrified Transportation," IEEE Transactions on Industrial Electronics, vol. 65, no. 8, pp. 6552-6559, Aug. 2018.

[10] C. Karnjanapiboon, K. Jirasereeamornkul, and V. Monyakul, "High efficiency battery management system for serially connected battery string," in IEEE International Symposium on Industrial Electronics. IEEE, 2009, pp. 1504-1509.

[11] C. Pinto, J. V. Barreras, E. Schaltz, and R. E. Araújo, "Evaluation of Advanced Control for Li-ion Battery Balancing Systems Using Convex Optimization," IEEE Transactions on Sustainable Energy, vol. 7, no. 4, pp. 1703-1717, Oct. 2016.

[12] A. Khaligh and Z. Li, "Battery, Ultracapacitor, Fuel Cell, and Hybrid Energy Storage Systems for Electric, Hybrid Electric, Fuel Cell, and Plug-In Hybrid Electric Vehicles: State of the Art," IEEE Transactions on Vehicular Technology, vol. 59, no. 6, pp. 2806-2814, Jul. 2010.

[13] S. Vazquez, S. M. Lukic, E. Galvan, L. G. Franquelo, and J. M. Carrasco, "Energy Storage Systems for Transport and Grid Applications," IEEE Transactions on Industrial Electronics, vol. 57, no. 12, pp. 3881-3895, Dec. 2010.

[14] B. H. Nguyen, R. German, J. P. F. Trovao, and A. Bouscayrol, "RealTime Energy Management of Battery/Supercapacitor Electric Vehicles Based on an Adaptation of Pontryagin's Minimum Principle," IEEE Transactions on Vehicular Technology, 2018.

[15] R. E. Araujo, R. de Castro, C. Pinto, P. Melo, and D. Freitas, "Combined Sizing and Energy Management in EVs With Batteries and Supercapacitors," IEEE Transactions on Vehicular Technology, vol. 63, no. 7, pp. 3062-3076, Sep. 2014.

[16] J. P. F. Trovão, M. Roux, E. Menard, and M. R. Dubois, "Energy- and Power-Split Management of Dual Energy Storage System for a ThreeWheel Electric Vehicle," IEEE Transactions on Vehicular Technology, vol. 66, no. 7, pp. 5540-5550, Jul. 2017.

[17] K. Alobeidli and V. Khadkikar, "A New Ultracapacitor State of Charge Control Concept to Enhance Battery Lifespan of Dual Storage Electric Vehicles," IEEE Transactions on Vehicular Technology, vol. 67, no. 11, pp. 10470-10481, Nov. 2018.

[18] A. Ostadi and M. Kazerani, "A Comparative Analysis of Optimal Sizing of Battery-Only, Ultracapacitor-Only, and Battery-Ultracapacitor Hybrid Energy Storage Systems for a City Bus," IEEE Transactions on Vehicular Technology, vol. 64, no. 10, pp. 4449-4460, Oct. 2015.

[19] L. Zhang, X. Hu, Z. Wang, F. Sun, J. Deng, and D. G. Dorrell, "Multiobjective Optimal Sizing of Hybrid Energy Storage System for Electric Vehicles," IEEE Transactions on Vehicular Technology, vol. 67, no. 2, pp. 1027-1035, Feb. 2018.

[20] J. Shen and A. Khaligh, "A Supervisory Energy Management Control Strategy in a Battery/Ultracapacitor Hybrid Energy Storage System," IEEE Transactions on Transportation Electrification, vol. 1, no. 3, pp. 223-231, Oct. 2015.

[21] E. Martinez-Laserna, E. Sarasketa-Zabala, I. V. Sarria, D. Stroe, M. Swierczynski, A. Warnecke, J. Timmermans, S. Goutam, N. Omar, and P. Rodriguez, "Technical Viability of Battery Second Life: A Study From the Ageing Perspective," IEEE Transactions on Industry Applications, vol. 54, no. 3, pp. 2703-2713, May 2018.

[22] H. H. Eldeeb, A. T. Elsayed, C. R. Lashway, and O. Mohammed, "Hybrid Energy Storage Sizing and Power Splitting Optimization for Plug-In Electric Vehicles," IEEE Transactions on Industry Applications, vol. 55, no. 3, pp. 2252-2262, May 2019.

[23] Thorsten Grun, Anna Smithb, Helmut Ehrenbergb, and Martin Doppelbauera, "Passive Hybrid Storage Systems: Influence of circuit and system design on performance and lifetime," in 12th International Renewable Energy Storage Conference, 2018.

[24] F. M. Ibanez, A. M. B. Florez, S. Gutiérrez, and J. M. Echeverrría, "Extending the Autonomy of a Battery for Electric Motorcycles," IEEE Transactions on Vehicular Technology, vol. 68, no. 4, pp. 3294-3305, Apr. 2019.

[25] A. Kuperman and I. Aharon, "Battery-ultracapacitor hybrids for pulsed current loads: A review," Renewable and Sustainable Energy Reviews, vol. 15, no. 2, pp. 981-992, Feb. 2011.

[26] Q. Zhang, W. Deng, and G. Li, "Stochastic Control of Predictive Power Management for Battery/Supercapacitor Hybrid Energy Storage Systems 
of Electric Vehicles," IEEE Transactions on Industrial Informatics, vol. 14, no. 7, pp. 3023-3030, Jul. 2018.

[27] N. Zhao, N. Schofield, R. Yang, and R. Gu, "Investigation of DC-Link Voltage and Temperature Variations on EV Traction System Design," IEEE Transactions on Industry Applications, vol. 53, no. 4, pp. 37073718, Jul. 2017.

[28] F. Baronti, G. Fantechi, R. Roncella, and R. Saletti, "High-Efficiency Digitally Controlled Charge Equalizer for Series-Connected Cells Based on Switching Converter and Super-Capacitor," IEEE Transactions on Industrial Informatics, vol. 9, no. 2, pp. 1139-1147, May 2013

[29] Y. Ye and K. W. E. Cheng, "Modeling and Analysis of Series-Parallel Switched-Capacitor Voltage Equalizer for Battery/Supercapacitor Strings," IEEE Journal of Emerging and Selected Topics in Power Electronics, vol. 3, no. 4, pp. 977-983, Dec. 2015.

[30] C.-C. Lin, H. Peng, J. W. Grizzle, and J.-M. Kang, "Power management strategy for a parallel hybrid electric truck," IEEE Transactions on Control Systems Technology, vol. 11, no. 6, pp. 839-849, Nov. 2003.

[31] Ahmed Ali and Dirk Söffker, "Towards Optimal Power Management of Hybrid Electric Vehicles in Real-Time: A Review on Methods, Challenges, and State-Of-The-Art Solutions," Energies, vol. 11, no. 3, p. 476, Feb. 2018

[32] S. Boyd and L. Vandenberghe, Convex optimization, 18th ed. Cambridge: Cambridge Univ. Press, 2015.

[33] M. Pourabdollah, B. Egardt, N. Murgovski, and A. Grauers, "Convex Optimization Methods for Powertrain Sizing of Electrified Vehicles by Using Different Levels of Modeling Details," IEEE Transactions on Vehicular Technology, vol. 67, no. 3, pp. 1881-1893, Mar. 2018.

[34] J. Platt, N. Moehle, J. D. Fox, and W. Dally, "Optimal Operation of a Plug-In Hybrid Vehicle," IEEE Transactions on Vehicular Technology, vol. 67, no. 11, pp. 10366-10377, Nov. 2018.

[35] C. Pinto, R. de Castro, J. V. Barreras, R. E. Araujo, and D. Howey, "Smart Balancing Control of a Hybrid Energy Storage System based on a Cell-to-Cell Shared Energy Transfer Configuration," in IEEE Vehicle Power and Propulsion Conference, Chicago, USA, 2018.

[36] M. Preindl, C. Danielson, and F. Borrelli, "Performance evaluation of battery balancing hardware," in European Control Conference (ECC), 2013, pp. 4065-4070

[37] J. V. Barreras, "Practical Methods in Li-ion Batteries: for simplified modeling, battery electric vehicle design, battery management system testing and balancing system control," PhD. Dissertation, University of Aalborg, 2017.

[38] C. Pinto, "Sizing and Energy Management of a Distributed Hybrid Energy Storage System for Electric Vehicles," PhD. Dissertation, University of Porto, 2018.

[39] B. Egardt, N. Murgovski, M. Pourabdollah, and L. J. Mardh, "Electromobility Studies Based on Convex Optimization: Design and Control Issues Regarding Vehicle Electrification," IEEE Control Systems, vol. 34, no. 2, pp. 32-49, Apr. 2014

[40] M. Grant and S. Boyd, "CVX: Matlab software for disciplined convex programming, version 2.1," 2018. [Online]. Available: http://cvxr.com/

[41] R. Tutuncu, K. Toh, and M. Todd, "Solving semidefinite-quadratic-linear programs using SDPT3," Mathematical Programming, vol. 95, pp. 189217, 2013.

[42] H. Li, F. Z. Peng, and J. S. Lawler, "A natural ZVS medium-power bidirectional DC-DC converter with minimum number of devices," IEEE Transactions on Industry Applications, vol. 39, no. 2, pp. 525-535, Mar. 2003.

[43] D. Linzen, S. Buller, E. Karden, and R. W. D. Doncker, "Analysis and evaluation of charge-balancing circuits on performance, reliability, and lifetime of supercapacitor systems," IEEE Transactions on Industry Applications, vol. 41, no. 5, pp. 1135-1141, Sep. 2005.

[44] F. Borrelli, A. Bemporad, and M. Morari, Predictive control linear and hybrid systems. Cambridge University Press, 2017.

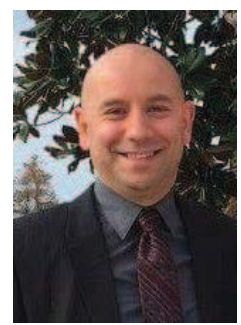

Ricardo de Castro (S'09, M'13, SM'19) was born in Porto, Portugal, in 1983. He received the Licenciatura and Ph.D. degrees in electrical and computers engineering from University of Porto, Portugal, in 2006 and 2013, respectively. During 2007-08, he was an entrepreneur with the WeMoveU project, targeting the development of powertrain control solutions for light electric vehicles. Since 2013, he has been with the German Aerospace Center (DLR), Institute of System Dynamics and Control (SR), where he is developing enabling technologies for electric mobility and autonomous driving. His research interests include vehicle dynamics, tire-road friction estimation, trajectory control, torque blending, platooning and battery-supercapacitor hybridization. Ricardo de Castro has been an expert evaluator for the European Union, Editor of IEEE Transactions on Vehicular Technology and Associate Editor of IEEE Access. $\mathrm{He}$ is the author of three patents and more than 60 papers in international journals, conferences and book chapters.

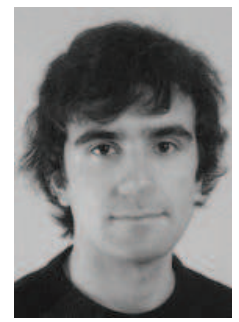

Cláudio Pinto was born in Porto, Portugal. He received the B.S. degree in electric engineering in 2010, the M.S. degree in 2012 and the Ph.D. in 2017 from University of Porto, Portugal. He is currently a control engineer at Continental Engineering Services. His research interests are power electronics, electric vehicles, and energy management of hybrid energy storage systems.

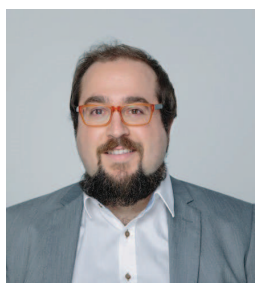

Jorge Varela Barreras (M'14) received the M.Sc. degree in electrical engineering from the University of Vigo, Spain, in 2010, and the M.Sc. and Ph.D. degrees in power electronics and battery management systems from Aalborg University, Aalborg, Denmark, in 2009 and 2017. In 2010, he cofounded an engineering consulting company. In 2011, he became a researcher at Aalborg University. From June 2016 to the end of 2018, he was a postdoctoral researcher in battery management at the University of Oxford, Oxford, U.K. In 2019 he became a senior battery researcher at Imperial College London, London, U.K. His research interests include e-mobility, lead acid, and lithium-ion battery electro-thermal modelling, simulation, testing, monitoring, balancing, and management systems. He is the joint chair of the IEEE UK and Ireland education society chapter, a fellow of the Faraday institution, a founder member of the Danish battery society, and a member of the editorial board of ETransportation by Elsevier, and Frontiers in Energy Research. He was a research member of common room of Kellogg College, Oxford, and chairman of the Oxford research staff society voice.

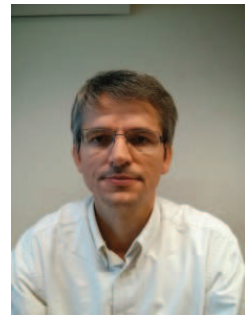

Rui Esteves Araújo (M'99) received the Electrical Engineering diploma, the M.Sc. and Ph.D. degrees from University of Porto, Porto, Portugal, in 1987, 1992, and 2001, respectively. From 1987 to 1988, he was an Electrotechnical Engineer in Project Department, Adira Company, Porto, Portugal, and from 1988 to 1989, he was researcher with INESC, Porto, Portugal. Since 1989, he has been with the University of Porto, where he is currently an Assistant Professor with the Department of Electrical and Computer Engineering, Faculty of Engineering, University of Porto. He is senior researcher in the INESC TEC, focusing on control theory and its industrial applications to motion control, electric vehicles and renewable energies. 


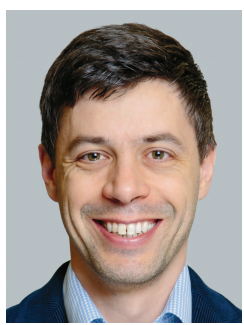

David A. Howey (M'10-SM'17) received the B.A. and M.Eng. degrees from Cambridge University, Cambridge, U.K., in 2002, and the Ph.D. degree from Imperial College London, London, U.K., in 2010. He is currently an Associate Professor in the Department of Engineering Science, University of Oxford, Oxford, U.K. His research interests focus on energy storage systems, including projects on model-based battery management, degradation, thermal management, and energy management for grid storage. 